\section{Primary cutaneous amyloidosis of the auricular concha - case report ${ }^{*}$}

\author{
Yasmin Gama Abuawad ${ }^{1}$ \\ Priscila Kakizaki ${ }^{1}$
}

Juliana Uchiyama ${ }^{1}$

Neusa Yuriko Sakai Valente ${ }^{1}$

\section{DOI: http:/ /dx.doi.org/10.1590/abd1806-4841.20175864}

\section{Dear Editor,}

Amyloidosis includes a group of diseases that share a common feature of the extracellular deposit of amyloid material within tissues. ${ }^{1}$ Primary amyloidosis is subdivided into macular, lichen amyloidosis and nodular forms. ${ }^{2}$ Amyloidosis of the auricular concha is a type of primary cutaneous amyloidosis that effects the outer ear. It is a rare disorder, characterized by the presence of asymptomatic or pruritic papules in the auricular concha, generally with no association with other types of cutaneous amyloidosis or systemic diseases. No consensus has been reached as to whether the disease represents a new entity of cutaneous amyloidosis or a subtype of lichen amyloidosis. ${ }^{1}$ We report a case of a 67 -year-old female patient, who complained of the appearance of pruritic papules on the right ear over the past two years. Dermatological examination revealed multiple normochromic papules of $1-2 \mathrm{~mm}$ in diameter in the right auricular concha (Figure 1). Other types of amyloidosis cutaneous lesions were not observed. Cutaneous biopsy was performed, and histopathology showed the deposit of homogeneous eosinophilic materials and the absence of birefringence of Congo Red stain when submitted to polarized light, corroborating with the diagnosis of amyloidosis of the auricular concha (Figures 2 and 3). Mometasone Furoate was topically applied, presenting a significant improvement in pruritis. The amyloidosis of the auricular concha is a rare form of primary cutaneous amyloidosis, which was first described in 1988, in which four adult patients presented papules in the outer ear and that were not associated with other cutaneous amyloidosis lesions. ${ }^{2,3}$ This disease mainly affects women between 40 and 70 years of age and appears as small papules that can be normochromic, yellowish, or erythematous, located anywhere on the outer ear, mainly in the auricular concha, and can be uni or bilateral. These papules are generally asymptomatic, however, in some cases, they can be pruritic. ${ }^{4}$ Differential diagnoses include seborrheic keratosis, viral warts, calluses, basal-cell carcinoma, adnexal neoplasms, and chronic erythematous lupus. ${ }^{4}$ There is no consensus if this condi-

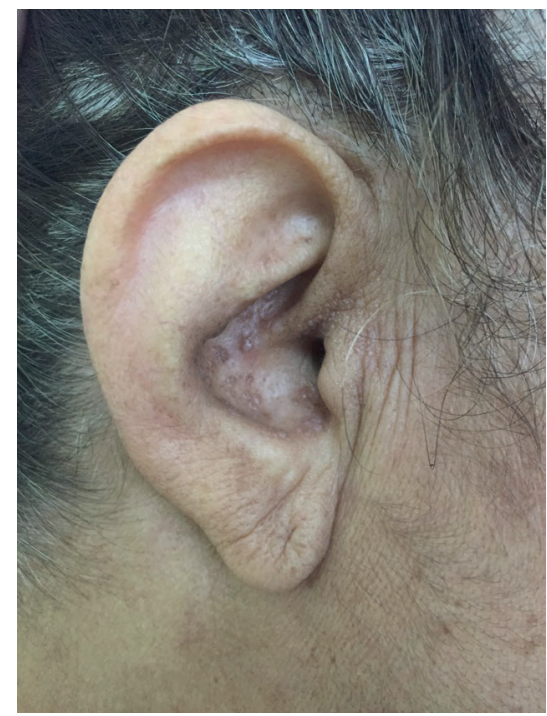

FiguRE 1: Multiple normochromic papules in the auricular concha and the external auditory canal of the right ear

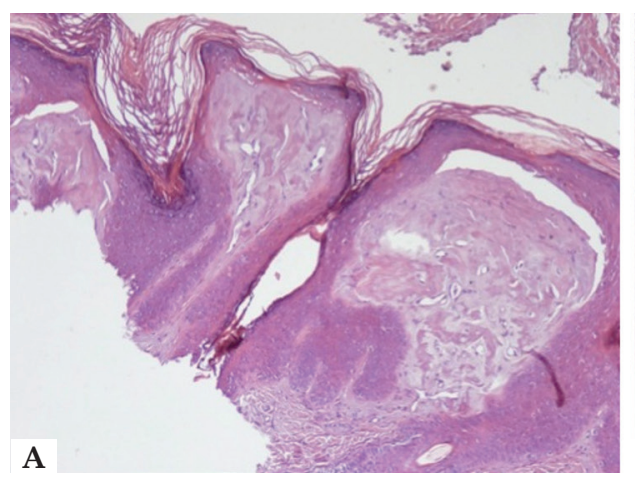

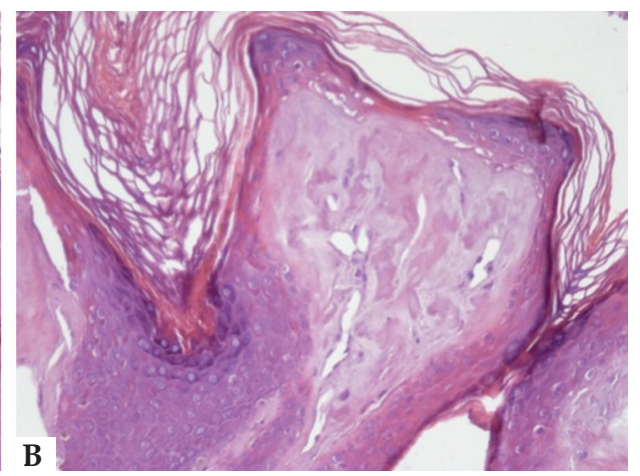

FIGURE 2:

A) Hematoxylin \& eosin, original magnified 100X: amorphous and eosinophilic nodular deposit on the papillary dermis; hyperkeratosis and atrophy of the epidermis above the lesion. B) Original, magnified 200X: lesion details

Received on 02.04 .2016

Approved by the Advisory Board and accepted for publication on 15.05.2016

* Work conducted at the Hospital do Servidor Público Estadual de São Paulo (HSPE), São Paulo, SP, Brazil.

Financial support: None.

Conflict of interests: None.

Dermatology Service at Hospital do Servidor Público Estadual de São Paulo (HSPE), São Paulo, SP, Brazil.

(O2017 by Anais Brasileiros de Dermatologia 


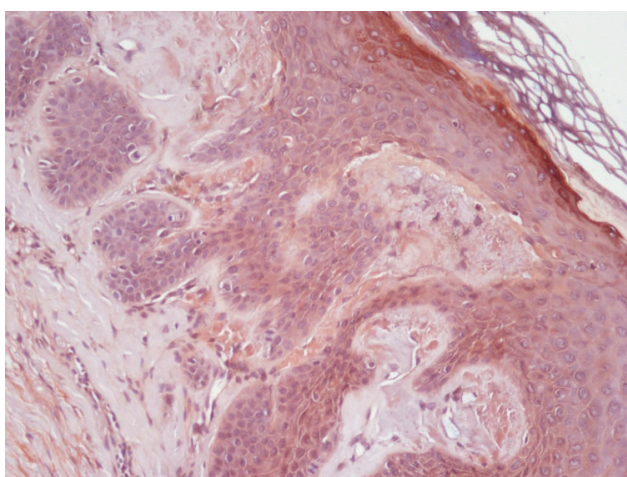

Figure 3: Original, magnified 200X - Congo red: Orange coloration. Absence of birefringence when submitted to polarized light

tion is in fact a new subtype of primary cutaneous amyloidosis or a variant of lichen amyloidosis. ${ }^{1,5}$ The histopathological analysis consists of a nodular deposit of amorphous, eosinophilic, and homogenous material in the papillary dermis. The overlaying epidermis is atrophic and can partially encompass the amyloid material, in thin collarettes, and can present hyperkeratosis. There is some conflicting evidence in the literature regarding the nature of the deposits. The first case reports suggest a collagenous nature of the material, as they were stained with Verhoeff-van Gieson and Periodic acid-Schiff (PAS) and not with Congo red, and presented electronic microscopy consistent with collagen deposit, and the lesions were called collagen papules of the auricular concha. ${ }^{4}$ However, the majority of the reported cases demonstrated that the material was stained with Crystal Violet and became orange-colored with Congo red, generally presenting positive birefringence when submitted to polarized light, thus suggesting the amyloid origin of such deposits. ${ }^{1,2,3,4}$ According to the author of the largest case study on this issue, they could represent two distinct entities, though clinically similar, which could have been clarified if immunohistochemistry had been used in the first cases. ${ }^{4}$ The material deposited in our patient presented a negative birefringence, which does not exclude the diagnosis of primary cutaneous amyloidosis, based on the clinical and histopathological findings. It is suggested that the amyloid material has an epidermal origin, since the immunohistochemical profile is positive for CK 34beta32, which corresponds to cytokeratins of high molecular weight, such as CK $1,5,10$, and 14, which react with the squamous epithelium, including the epidermis. ${ }^{4}$ There is no specific treatment capable of removing the amyloid deposits. As the papules of the auricular concha are mostly asymptomatic, localized, and superficial, then electrocoagulation, curettage, and excision seem to be sufficient for a good aesthetic result. ${ }^{2,4}$

\section{REFERENCES}

1. Shimauchi T, Shin JH, Tokura Y. Primary cutaneous amyloidosis of the auricular concha: Case report and review of published work. J Dermatol. 2006;33:128-31.

2. Neff AG, McCuin JB, Mutasim DF. Papular amyloidosis limited to the ears. J Am Acad Dermatol. 2010;62:1078-9.

3. Hicks BC, Weber PJ, Hashimoto K, Ito K, Koreman DM. Primary cutaneous amyloidosis of the auricular concha. J Am
Acad Dermatol. 1988;18:19-25.

4. Wenson SF, Jessup CJ, Johnson MM, Cohen LM, Mahmoodi M. Primary cutaneous amyloidosis of the external ear: a clinicopathological and immunohistochemical study of 17 cases. J Cutan Pathol. 2012;39:263-9.

5. Bakos L, Weissbluth ML, Pires AK, Müller LF. Primary amyloidosis of the concha. J Am Acad Dermatol. 1989;20:524-5.

\author{
MAILING ADDRESS: \\ YASMIN GAMA ABUAWAD \\ AVENIDA IBIRAPUERA, 981- VILA CLEMENTINO \\ 04029-000 - SÃo PAULO, SP -BRAZIL \\ E-MAIL:YASMIN_GAMA@YAHOO.COM.BR
}

How to cite this article: Abuawad YG, Uchiyama J, Kakizaki P, Valente NYS. Primary Cutaneous Amiloidosis of the Auricular Concha- Case Report. An Bras Dermatol. 2017;92(3):433-4.

\section{Interstitial granulomatous dermatitis with arthritis*}

Juliana Lacerda Reis Ucelli ${ }^{1} \quad$ Fabiana de Sousa Borges Rudolph ${ }^{1}$ Daniel Lago Obadia ${ }^{1,2}$

Carla da Fontoura Dionello ${ }^{3}$

DOI: http://dx.doi.org/10.1590/abd1806-4841.20175973

\section{Dear Editor,}

Interstitial granulomatous dermatitis is a rare, idiopathic disease with typical histopathological characteristics and with a variable clinical expression. ${ }^{1}$ In 1993, Ackerman et al. proposed the term interstitial granulomatous dermatitis with arthritis (IGDA), to describe the association of the cutaneous cords with changes in the musculoskeletal system. ${ }^{2,3}$ However, other cutaneous lesions have also been described, such as erythematous or hyperchromic papules, subcutaneous plaques, and lesions with annular shapes, which generally affect the side walls of the thorax, armpits, abdomen, and medial surface of the thighs..$^{3-5}$

Received on 26.04.2016

Approved by the Advisory Board and accepted for publication on 05.11.2016

* Work conducted at the Hospital Central do Exército (HCE), Rio de Janeiro, RJ, Brazil.

Financial support: None.

Conflict of interests: None.

Tropical Dermatology Service, Hospital Central do Exército (HCE), Rio de Janeiro, RJ, Brazil.

2 Dermatology Service, Hospital Universitário Pedro Ernesto - Universidade do Estado do Rio de Janeiro (HUPE-UERJ), Rio de Janeiro, RJ, Brazil.

Rheumatology Service, Hospital Central do Exército, Rio de Janeiro, RJ, Brazil.

@2017 by Anais Brasileiros de Dermatologia 